Article

\title{
Asymmetric Synthesis of Tetrahydroisoquinoline Derivatives through 1,3-Dipolar Cycloaddition of $C, N$-Cyclic Azomethine Imines with Allyl Alkyl Ketones
}

\author{
Guipeng Feng ${ }^{1,2}$, Guoyang $\mathrm{Ma}^{2}$, Wenyan Chen ${ }^{2}$, Shaohong $\mathrm{Xu}^{2}{ }^{2}$, Kaikai Wang ${ }^{2, * \mathbb{D}}$ and Shaoyan Wang ${ }^{1, *}$ \\ 1 School of Chemical Engineering, University of Science and Technology Liaoning, Anshan 114051, China; \\ fengguipengheda@163.com \\ 2 School of Pharmacy, Xinxiang University, Xinxiang 453000, China; maguoyang0903@gmail.com (G.M.); \\ c15736992481@163.com (W.C.); xu_shaohong@126.com (S.X.) \\ * Correspondence: wangkaikai@xxu.edu.cn (K.W.); aswsy64@163.com (S.W.)
}

check for updates

Citation: Feng, G.; Ma, G.; Chen, W.; Xu, S.; Wang, K.; Wang, S.

Asymmetric Synthesis of

Tetrahydroisoquinoline Derivatives through 1,3-Dipolar Cycloaddition of $\mathrm{C}, \mathrm{N}$-Cyclic Azomethine Imines with Allyl Alkyl Ketones. Molecules 2021, 26, 2969. https://doi.org/10.3390/ molecules26102969

Academic Editor: Fangrui Zhong

Received: 12 April 2021

Accepted: 12 May 2021

Published: 17 May 2021

Publisher's Note: MDPI stays neutral with regard to jurisdictional claims in published maps and institutional affiliations.

Copyright: (C) 2021 by the authors Licensee MDPI, Basel, Switzerland. This article is an open access article distributed under the terms and conditions of the Creative Commons Attribution (CC BY) license (https:/ / creativecommons.org/licenses/by/ $4.0 /)$.

\begin{abstract}
A [3 + 2] 1,3-Dipolar cycloaddition of $C, N$-cyclic azomethine imines with allyl alkyl ketones has been achieved. The reaction proceeds under mild conditions and tolerates a wide range of functional groups. An array of tetrahydroisoquinoline derivatives is generally constructed with good diastereoselectivities and enantioselectivities (up to $>25: 1 \mathrm{dr},>95 \%$ ee). Moreover, the absolute configuration of the product was previously determined by using the quantum electronic circular dichroism calculation and ECD spectrum method.
\end{abstract}

Keywords: 1,3-dipolar cycloaddition; asymmetric; azomethine imines

\section{Introduction}

A variety of isoquinoline alkaloids [1-3] exist in many natural products and drugs, and have a broad range of clinical applications, exhibiting a broad range of biological activities such as antitumor, anti-HIV, antibiotic, antifungal, antivirus, anti-inflammatory, anticoagulation, and bronchodilation, and can also act on the central nervous system [4-8]. In particular, it is tremendously noteworthy that all the above-illustrated bioactive tetrahydroisoquinolines have a chiral stereocenter at the C1-position [9-12]. Such representative examples include (S)-salsolidine [13], (S)-carnegine [14], (S)-xylopinine [15] (in Figure 1), and so on. Novel $C, N$-cyclic azomethine imines as efficient 1,3-dipoles [16,17], are readily accessible, stable compounds that have been employed recently in various metal-catalyzed and organocatalytic 1,3-dipolar cycloadditions (1,3-DCs) [18-21]. These dipoles can be easily prepared and give access to pharmaceutically attractive chiral substituted tetrahydroisoquinoline skeletons.<smiles>COc1cc2c(cc1OC)C(C)NCC2</smiles>

(S)-salsolidine<smiles>COc1cc2c(cc1OC)[C@@H](C)N(C)CC2</smiles>

(S)-carnegine

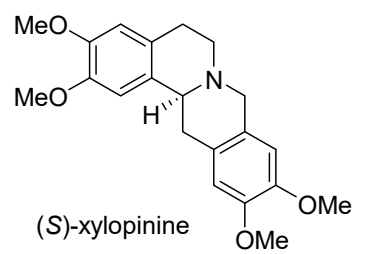

Figure 1. Examples of bioactive natural products containing chiral C1-substituted tetrahydroisoquinolines.

In 2010, the Maruoka group uncovered a promising example of using $C, N$-cyclic azomethine imines as prochiral electrophiles to react with $\alpha, \beta$-unsaturated aldehydes to construct a tetrahydroisoquinoline scaffold catalyzed by a titanium-BINOLate complex [22]. Shortly after, the Maruoka group disclosed the first example of using of vinyl ethers and 
$\mathrm{C}, \mathrm{N}$-cyclic azomethine imines catalyzed by chiral Brønsted acids to synthesize tetrahydroisoquinolines through the enantioselective organocatalytic inverse-electron-demand 1,3-DCs [23]. In 2014, the Wang group developed $C, N$-cyclic azomethine imines with $\alpha, \beta-$ unsaturated aldehydes through dienamine-mediated enantioselective [3+2] 1,3-dipolar cycloaddition catalyzed by a chiral prolinol silyl ether catalyst [24,25]. In addition, the $C, N-$ cyclic azomethine imine substrates were recently used in 1,3-DCs with $\mathrm{N}$-arylmaleimides, allenoates, azlactones, bromo-substituted Morita-Baylis-Hillman adducts of isatins, $\alpha, \beta-$ unsaturated nitriles, 3-nitroindoles, ortho-quinone methides through [3+2] or [4+3] annulation reactions [26-30] and catalyst free [5 + 1] cycloaddition with isocyanides [31], and with Morita-Baylis-Hillman carbonates by phosphine catalysts or with $N$-benzyl azomethine ylide or with azaoxyallyl cations through [3 + 3] cycloaddition [32-34], and $[3+1]$ cycloaddition with isocyanides (in Scheme 1a) [35]. However, to the best of our knowledge, no example of a catalytic asymmetric 1,3-dipolar cycloaddition reaction using allyl alkyl ketones with $C, N$-cyclic azomethine imines has been reported. Previous success by the Chen group, using chiral primary amine catalytic asymmetric $\gamma$-regioselective vinylogous Michael addition of allyl alkyl ketones with maleimides through dienamine catalysis, has been developed (in Scheme 1b) [36]. Herein, we report the first chiral primary amine-catalyzed enantioselective [3 + 2] 1,3-dipolar cycloaddition of allyl alkyl ketones with $\mathrm{C}, \mathrm{N}$-cyclic azomethine imines to give a novel class of dinitrogen-fused heterocycles combining the biologically important tetrahydroisoquinoline core and pyrazolidine core (in Scheme 1c).

(a) previous work of $C, N$-cyclic azomethine Imines

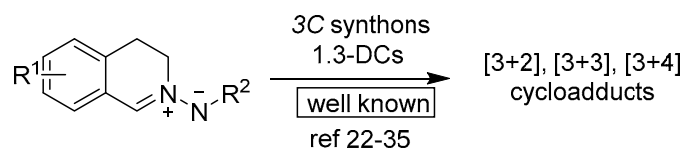

(b) previous work of allyl alkyl ketones

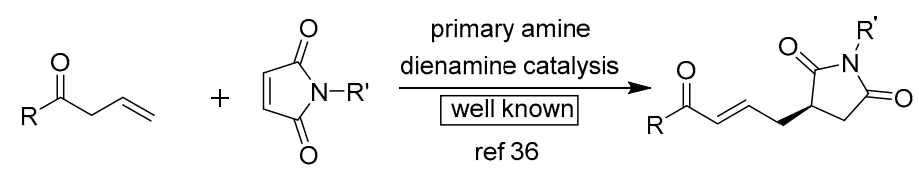

(c) this work

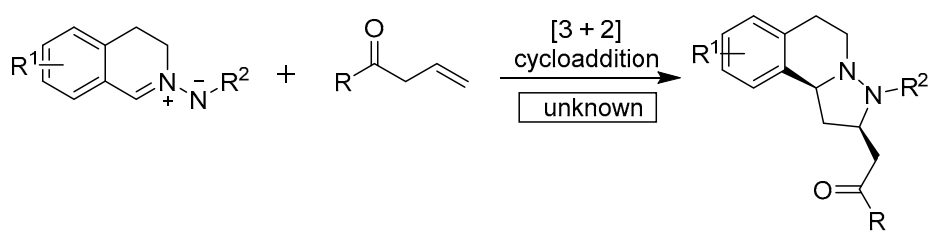

Scheme 1. Previous reports and our protocol.

\section{Results}

In our initial attempt, we first examined the reaction of $\mathrm{N}, \mathrm{N}$-cyclic azomethine imine $\mathbf{1}$ with deconjugated 3-enone $\mathbf{5 a}$ in the presence of DPEN catalyst $\mathbf{C 1}$ (Table 1 ) in $\mathrm{CHCl}_{3}$, but no desired product was observed even at a higher temperature. We then turned our attention to $\mathrm{C}, \mathrm{N}$-cyclic azomethine imines 2, 3 and 4a. Unfortunately, no matter what the temperature of the reaction raised from rt to reflux, no desired cycloaddition adduct was observed when we employed the 2 and 3 dipoles. To our delight, the reaction between $\mathrm{C}, \mathrm{N}$-cyclic azomethine imine $\mathbf{4 a}$ and deconjugated 3-enone 5a proceeded smoothly to give the desired product in high yield ( $85 \%$ yield, $62 \%$ ee and dr 3:2, entry 1, Table 1 ) and the reaction could not afford the desired product if no acid or no catalyst were added to the reaction [18] (entries 2 and 3). The results indicated that catalysts with acids are critical 
for the cycloaddition reaction. In addition, the $\beta, \gamma-\mathrm{C}=\mathrm{C}$ bond could act as an inducing group for the formation of more stable extended dienamine species from deconjugated 3 -enone substrates $5 \mathbf{a}$ and activating the $\gamma$-site and furnishing the following vinylogous 1,3-DCs process.

Table 1. Optimization of reaction conditions ${ }^{\mathrm{a}}$.

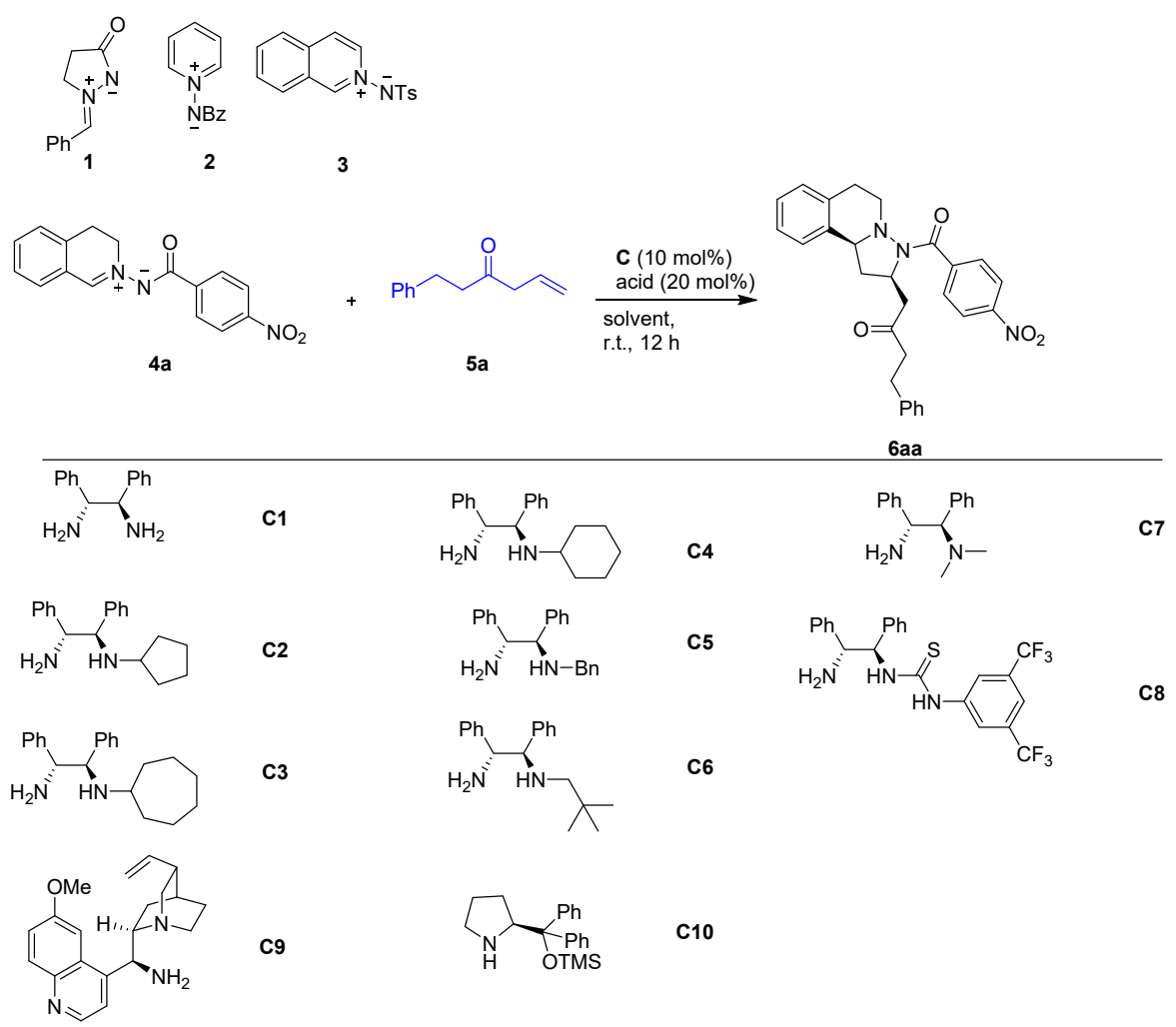

\begin{tabular}{|c|c|c|c|c|c|c|}
\hline Entry & Solvent & Catalyst & Acid & Yield $(\%)^{b}$ & ee $(\%)^{c}$ & $\mathrm{dr}^{\mathrm{d}}$ \\
\hline 1 & $\mathrm{CHCl}_{3}$ & $\mathrm{C} 1$ & benzoic acid & 85 & 62 & $3: 2$ \\
\hline 2 & $\mathrm{CHCl}_{3}$ & $\mathrm{C} 1$ & none & n.r. & - & - \\
\hline 3 & $\mathrm{CHCl}_{3}$ & none & benzoic acid & n.r. & - & - \\
\hline 4 & $\mathrm{CHCl}_{3}$ & $\mathrm{C} 2$ & benzoic acid & 89 & 80 & $12.5: 1$ \\
\hline 5 & $\mathrm{CHCl}_{3}$ & $\mathrm{C} 3$ & benzoic acid & 91 & 76 & $>25: 1$ \\
\hline 6 & $\mathrm{CHCl}_{3}$ & $\mathrm{C} 4$ & benzoic acid & 90 & 72 & $>25: 1$ \\
\hline 7 & $\mathrm{CHCl}_{3}$ & C5 & benzoic acid & 86 & 38 & $>25: 1$ \\
\hline 8 & $\mathrm{CHCl}_{3}$ & C6 & benzoic acid & 85 & 59 & $>25: 1$ \\
\hline 9 & $\mathrm{CHCl}_{3}$ & $\mathrm{C} 7$ & benzoic acid & 87 & 44 & $>25: 1$ \\
\hline 10 & $\mathrm{CHCl}_{3}$ & $\mathrm{C} 8$ & benzoic acid & 88 & 11 & $5: 1$ \\
\hline 11 & $\mathrm{CHCl}_{3}$ & $\mathrm{C} 9$ & benzoic acid & 56 & 20 & $>25: 1$ \\
\hline 12 & $\mathrm{CHCl}_{3}$ & $\mathrm{C} 10$ & benzoic acid & n.r. & - & - \\
\hline 13 & Toluene & $\mathrm{C} 2$ & benzoic acid & 90 & 85 & $1: 1$ \\
\hline 14 & DCE & $\mathrm{C} 2$ & benzoic acid & 91 & 80 & $25: 1$ \\
\hline 15 & $\mathrm{CH}_{3} \mathrm{CN}$ & $\mathrm{C} 2$ & benzoic acid & 72 & 28 & $2: 1$ \\
\hline 16 & THF & $\mathrm{C} 2$ & benzoic acid & 65 & 50 & $6: 1$ \\
\hline 17 & Dioxane & $\mathrm{C} 2$ & benzoic acid & 87 & 77 & $1: 1$ \\
\hline 18 & $\mathrm{Et}_{2} \mathrm{O}$ & $\mathrm{C} 2$ & benzoic acid & trace & - & - \\
\hline 19 & EA & $\mathrm{C} 2$ & benzoic acid & 74 & 70 & $1: 1$ \\
\hline 20 & DCE & $\mathrm{C} 2$ & $o$-fluorobenzoic acid & $92(85)^{e}$ & $84(64)^{e}$ & $10: 1$ \\
\hline 21 & DCE & $\mathrm{C} 2$ & salicylic acid & 90 & 65 & $4: 1$ \\
\hline 22 & DCE & $\mathrm{C} 2$ & $p$-nitrobenzoic acid & 82 & 68 & $15.7: 1$ \\
\hline 23 & DCE & $\mathrm{C} 2$ & $p$-methoxybenzoic acid & 75 & 82 & $6: 1$ \\
\hline
\end{tabular}

${ }^{a}$ Unless noted otherwise, reactions were performed with $4 \mathbf{a}(0.1 \mathrm{mmol}), 5 \mathrm{a}(0.2 \mathrm{mmol})$, amine $\mathbf{C}(10 \mathrm{~mol} \%)$, and acid (20 mol $\left.\%\right)$ in solvent $(1 \mathrm{~mL})$ at rt. ${ }^{\mathrm{b}}$ Isolated yield. ${ }^{\mathrm{c}}$ Determined by chiral HPLC analysis. ${ }^{\mathrm{d}}$ Determined by crude NMR analysis. ${ }^{\mathrm{e}}$ The reaction was conducted at $0{ }^{\circ} \mathrm{C}$ for $24 \mathrm{~h}$. 
We then turned our attention towards the use of chiral primary amine catalyst to improve the reaction enantioselectivity and diastereoselectivity. The reaction was tested in the presence of a number of primary amine catalysts (entries 4-10). The corresponding product 6aa was then isolated in high yield (89\%), good enantioselectivity (80\% ee), and with good diastereoselectivity ( $\mathrm{dr}$ 12.5:1) through $\mathrm{C} 2$ catalyst in $\mathrm{CHCl}_{3}$ at room temperature (entry 4). In contrast, the reaction afforded poor to moderate enantioselectivity (11-76\%) when used with other catalysts (entries 5-11). The chiral prolinol silyl ethers as the catalyst could not produce the product (entry 12). A screening of the solvents showed that performing the reaction to improve the ee and the dr (entry 13-19) with C2 as the catalyst. The reaction proceeded with higher yield (91\%) and good enantioselectivity (80\%) and excellent diastereoselectivity (dr 25:1) in DCE at room temperature (entry 14). However, only poor or moderate diastereoselectivities were observed in other solvents (entry 13, 15-19). Furthermore, the effect of acid additives was also studied. The presence of $20 \mathrm{~mol} \%$ $o$-fluorobenzoic acid (OFBA) enhanced the ee value to $84 \%$ and the yield also increased to $92 \%$ (entry 20). A screening of the temperature showed that performing the reaction at $0{ }^{\circ} \mathrm{C}$ reduced the ee value and the yield (entry 20). The yield and stereoselectivity could not be further improved when the reaction used the other acid additives (entries 21-23). On the basis of the above-mentioned results, the reaction conditions were established to 1.0 equivalent of 4, 2.0 equivalents of $5,10 \mathrm{~mol} \%$ of $\mathbf{C} 2$ and $20 \mathrm{~mol} \%$ of OFBA in DCE at room temperature for $12 \mathrm{~h}$.

\section{Discussion}

With the optimized conditions in hand, the generality of the reaction was evaluated. A range of substrates was shown to be compatible with the developed protocol for the [3+2] cycloaddition of $C, N$-cyclic azomethine imines to allyl alkyl ketone by using $\mathbf{C} 2$ as catalyst. As summarized in Figure 2 (Figures S2 and S3 Supplementary Material, respectively), not only aromatic alkyl allyl ketones but also long aliphatic chain allyl ketones could all be employed successfully to afford the products 6aa-ah in high yields (88-96\%), moderate to high enantioselectivities (50-96\%), and high diastereoselectivities (dr 10:1 to >25:1) From these results, we found that the conditions were applicable to a wide variety of allyl alkyl ketones. With this promising result in hand, we then investigated the generality of the $\mathrm{C}, \mathrm{N}$-cyclic azomethine imines. The influence of the substituent of the benzoyl group on the nitrogen was examined. The benzoyl group bearing electron-withdrawing or -donating groups at the para position and meta position afforded the corresponding products in high yields and steroselectivities (6ba to 6 ga). We found that some electron-withdrawing groups $\left(-\mathrm{NO}_{2},-\mathrm{Cl},-\mathrm{Br}\right)$ on the aromatic moiety were more effective than some donating groups $\left(-\mathrm{CH}_{3},-\mathrm{OCH}_{3}, 3,5-\mathrm{Me}_{2}\right)$ to afford the products in yields and steroselectivities, respectively (6aa to 6ga). From these results, it was determined that the electron density of the $N^{\prime}$-acyl moiety played an important role in trapping the $\beta$-position of the carbon-carbon double bond intermediate for the 1,3-DCs. This study prompted us to examine the influence of structurally different $N^{\prime}$-acyl moiety azomethine imines. The furoyl and naphthoyl groups on the nitrogen were also tolerated, giving the desired products in high yields, moderate enantioselectivities, and high diastereoselectivities, respectively (6ha 95\% yield, 60\% ee, dr $>25: 1$ and 6 ia $93 \%$ yield, $71 \%$ ee, $\mathrm{dr}>25: 1$ ). An increase in the steric bulk of the $N^{\prime}$-acyl moiety was also tolerated to afford the product 6 ja in high yields (90\%) with $72 \%$ ee value and dr 10:1. 


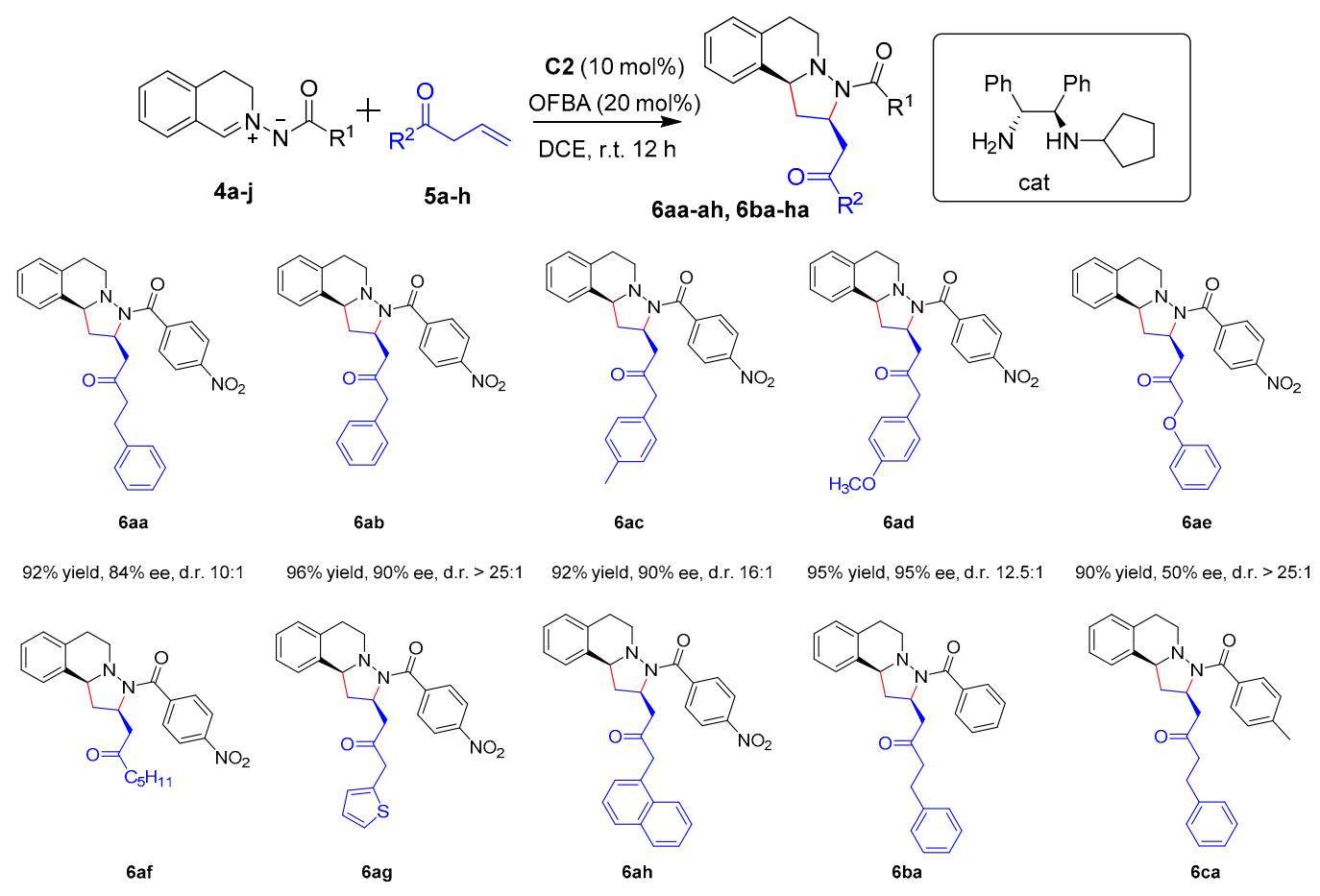

$95 \%$ yield, $85 \%$ ee, d.r. $>25: 1$

$93 \%$ yield, $85 \%$ ee, d.r. $>25: 1 \quad 88 \%$ yield, $75 \%$ ee, d.r. $10: 1$

$93 \%$ yield, $69 \%$ ee, d.r. $>25: 1 \quad 90 \%$ yield, $80 \%$ ee, d.r. $>25: 1$

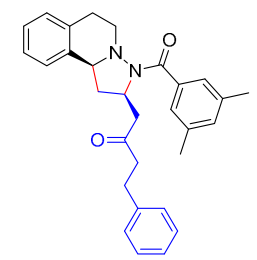

$6 \mathrm{da}$

$86 \%$ yield, $64 \%$ ee, d.r. $>25: 1$

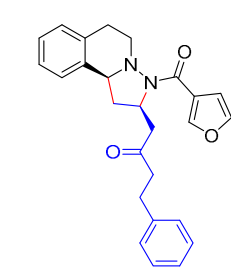

6ha

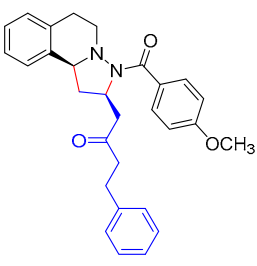

6 e

$90 \%$ yield, $70 \%$ ee, d.r. $>25: 1$

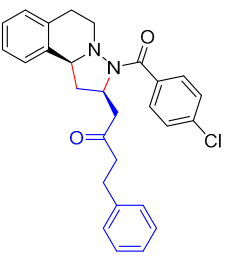

$6 \mathrm{fa}$

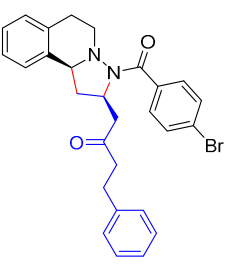

$6 \mathrm{ga}$

$94 \%$ yield, $76 \%$ ee, d.r. $>25: 1 \quad 92 \%$ yield, $83 \%$ ee, d.r. $>25: 1$

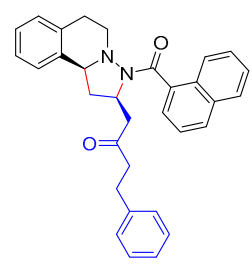

6ia

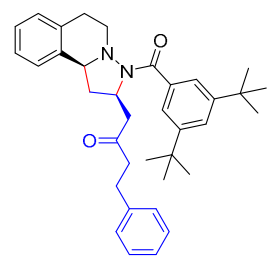

$6 j a$

$95 \%$ yield, $60 \%$ ee, d.r. $>25: 1 \quad 93 \%$ yield, $71 \%$ ee, d.r. $>25: 1 \quad 90 \%$ yield, $72 \%$ ee, d.r. $10: 1$

Figure 2. Substrate scope of the double 1,3-dipolar cycloaddition ${ }^{\mathrm{a}}$. ${ }^{\mathrm{a}}$ Unless noted otherwise, reactions were performed with $4(0.1 \mathrm{mmol}), 5(0.2 \mathrm{mmol})$, amine C2 $(10 \mathrm{~mol} \%)$, and OFBA $(20 \mathrm{~mol} \%)$ in DCE $(1 \mathrm{~mL})$ at rt.

As we failed to obtain single crystals suitable for X-ray crystallographic analysis to determine the absolute configuration of the products, the electronic circular dichroism (ECD) spectrum of chiral product $6 \mathbf{b a}$ was recorded in methanol and compared with the theoretically calculated results [37-39]. As depicted in Figure 3, the experimental ECD spectrum matched quite well to the calculated one of $(R, S)-6 \mathbf{b a}$. Therefore, the stereogenic center of product $\mathbf{6 b a}$ is probably in the $(R, S)$ configuration. 


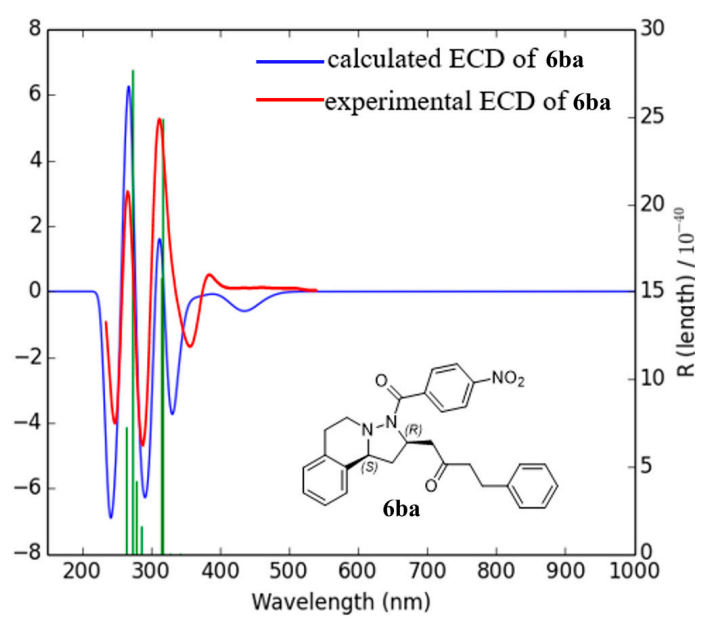

Figure 3. Comparison of the experimental ECD spectrum of chiral $\mathbf{6 b a}$ (the red line) with the calculated one of $(R, S)-6 \mathbf{b a}$ (the blue line). The green line is the position of the peak in horizontal axis.

As shown in Scheme 2, we proposed a plausible catalytic cycle to explain the reaction mechanism. The condensation of a chiral primary amine catalyst with allyl phenylethyl ketone $5 \mathrm{a}$ would lead to the formation of the iminium-ion, which could form the dienamine intermediate $\mathbf{A}$ [40-42]. The dienamine intermediate $\mathbf{A}$ reacts with the $C, N$-cyclic azomethine $4 \mathbf{a}$ by a 1,3-dipolar cycloaddition to generate the polycyclic intermediate $\mathbf{B}$. Subsequently, an acid-catalyzed elimination step converts intermediate $\mathbf{B}$ to the final product 6aa.

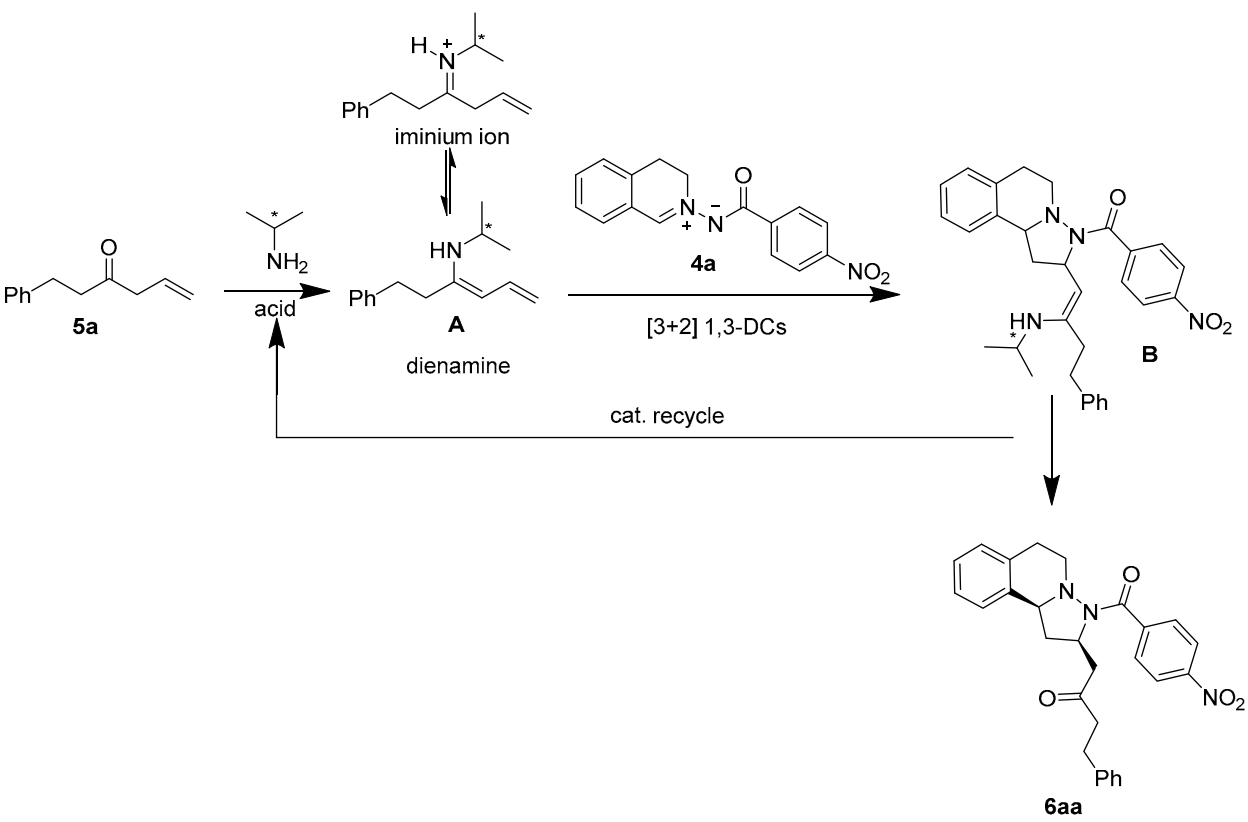

Scheme 2. Plausible mechanism.

\section{Materials and Methods}

NMR data were obtained for ${ }^{1} \mathrm{H}$ at $400 \mathrm{MHz}$ or $600 \mathrm{MHz}$, and for ${ }^{13} \mathrm{C}$ at $100 \mathrm{MHz}$ or $150 \mathrm{MHz}$. The data are presented as follows: chemical shift was reported in ppm from tetramethylsilane with the solvent resonance as the internal standard in $\mathrm{CDCl} 3$ solution, integration, multiplicity $(\mathrm{br}=$ broad, $\mathrm{s}=$ singlet, $\mathrm{d}=$ doublet, $\mathrm{t}=$ triplet, $\mathrm{q}=$ quartet, $\mathrm{m}$ $=$ multiplet) and coupling constant in Hertz (Hz). ESI HRMS was recorded on a Waters SYNAPT G2. In each case, enantiomeric excesses (ee) were determined by chiral highperformance liquid chromatography (chiral HPLC) that were Daicel Chiralpak AD-H 
Column $(250 \times 4.6 \mathrm{~mm})$, Chiralpak IA Column $(250 \times 4.6 \mathrm{~mm})$, or Chiralpak IC Column $(250 \times 4.6 \mathrm{~mm})$. UV detection was monitored at $220 \mathrm{~nm}$ or $254 \mathrm{~nm}$. Optical rotation was measured in $\mathrm{CHCl} 3$ solution at $20^{\circ} \mathrm{C}$. Column chromatography was performed on silica gel (200-300 mesh) eluting with ethyl acetate and petroleum ether. TLC was performed on glass-backed silica plates. UV light, $\mathrm{I}_{2}$, and solution of potassium permanganate were used to visualize products. All chemicals were used without purification as commercially available unless otherwise noted. Petroleum ether (PE) and ethyl acetate (EtOAc) were distilled. THF was freshly distilled from sodium/benzophenone before use. Experiments involving moisture and/or air sensitive components were performed under a positive pressure of argon in oven-dried glassware equipped with a rubber septum inlet. Dried solvents and liquid reagents were transferred by oven-dried syringes.

The 1,3-dipoles of $\mathbf{1}$ [43], 2 [44], 3 [45] and 4 [46-51] were synthesized according to the literature methods. The substrates $5 \mathbf{a}-\mathbf{h}$ were prepared according to the literature procedures [36,52-57]. Catalyst $\mathbf{C} \mathbf{1}$ was commercially available. Catalysts $\mathbf{C} 2-\mathbf{C} 8$ were synthesized according to the literature procedures $[58,59]$. The $C, N$-cyclic azomethine imines 4 $(0.1 \mathrm{mmol})$, catalyst C2 $(2.8 \mathrm{mg}, 0.01 \mathrm{mmol}), o$-fluorobenzoic acid $(2.8 \mathrm{mg}, 0.02 \mathrm{mmol})$ were dissolved in DCE $(1.0 \mathrm{~mL})$ and allyl ketone $5(0.2 \mathrm{mmol})$ was added. Then, the mixture was stirred at $\mathrm{rt}$ for $12 \mathrm{~h}$. After completion, the mixture was evaporated and the resulting crude residue was purified by column chromatography on silica gel eluting with petroleum ether/ethyl acetate (10:1 to 5:1) to afford the chiral product 6 .

\section{Conclusions}

In conclusion, we have developed the first chiral primary amine-catalyzed enantioselective [3+2] 1,3-dipolar cycloaddition of allyl alkyl ketones with $C, N$-cyclic azomethine imines via induced dienamine catalysts to give a novel class of dinitrogen-fused heterocycles combining the biologically important tetrahydroisoquinoline core and pyrazolidine core. The reaction affords a tetrahydroisoquinoline derivative in high yield with moderate to high enantioselectivities (up to $96 \%$ ) and high diastereoselectivities. In addition, this reaction provides an efficient method for constructing diverse and complex chiral tetrahydroisoquinolines compounds. Research into further applications of this enantioselective 1,3-dipolar cycloaddition with $\mathrm{C}, \mathrm{N}$-cyclic azomethine imines is in progress.

Supplementary Materials: The following are available online. Figure S1: General procedure for the preparation of the $C, N$-cyclic azomethines imines and its analogs, Figure S2: General procedure for catalytic asymmetric 1,3-DCs, Figure S3: Copies of NMR spectra and HPLC spectra.

Author Contributions: G.F., G.M., W.C. and S.X. participated in the synthesis, purification and characterization of the new compound. K.W. and S.W. participated in the interpretation of spectroscopy of the new compounds and the review of the manuscript. K.W. and S.W. participated in the interpretation of the results, writing, revision and correspondence to the Journal of Molecules until the manuscript was accepted. All authors have read and agreed to the published version of the manuscript.

Funding: This research was funded by the NSFC (21801214) and Funding of College Students Innovation and Entrepreneurship Training Program of Henan province (S202011071009).

Institutional Review Board Statement: Not applicable.

Informed Consent Statement: Not applicable.

Data Availability Statement: Data are contained within the article or Supplementary materials.

Acknowledgments: We are grateful for the financial support from Funding of College Students Innovation and Entrepreneurship Training Program of Henan province (S202011071009).

Conflicts of Interest: The authors declare no conflict of interest. The funders had no role in the design of the study; in the collection, analyses, or interpretation of data; in the writing of the manuscript, or in the decision to publish the results.

Sample Availability: Samples of the compounds are available from the authors. 


\section{References}

1. Kouznetsov, V.V.; Ortiz-Villamizar, M.C.; Mendez-Vargas, L.Y.; Puerto Galvis, C.E. A Review on Metal-Free Oxidative $\alpha$-Cyanation and Alkynylation of $\mathrm{N}$-Substituted Tetrahydroisoquinolines as a Rapid Route for the Synthesis of Isoquinoline Alkaloids. Curr. Org. Chem. 2020, 24, 809-816. [CrossRef]

2. Chrzanowska, M.; Grajewska, A.; Rozwadowska, M.D. Asymmetric Synthesis of Isoquinoline Alkaloids: 2004-2015. Chem. Rev. 2016, 116, 12369-12465. [CrossRef] [PubMed]

3. Bhadra, K.; Kumar, G.S. Therapeutic Potential of Nucleic Acid-Binding Isoquinoline Alkaloids: Binding Aspects and Implications for Drug Design. Med. Res. Rev. 2011, 31, 821-862. [CrossRef] [PubMed]

4. Shang, X.-F.; Yang, C.-J.; MorrisNatschke, S.L.; Li, J.-C.; Yin, X.-D.; Liu, Y.-Q.; Guo, X.; Peng, J.-W.; Goto, M.; Zhang, J.-Y.; et al. Biologically active isoquinoline alkaloids covering 2014-2018. Med. Res. Rev. 2020, 40, 2212-2289. [CrossRef] [PubMed]

5. Li, D.-D.; Yu, P.; Xiao, W.; Wang, Z.-Z.; Zhao, L.-G. Berberine: A Promising Natural Isoquinoline Alkaloid for the Development of Hypolipidemic Drugs. Curr. Top. Med. Chem. 2020, 20, 2634-2647. [CrossRef]

6. Qing, Z.-X.; Yang, P.; Tang, Q.; Cheng, P.; Liu, X.-B.; Zheng, Y.-J.; Liu, Y.-S.; Zeng, J.-G. Isoquinoline Alkaloids and Their Antiviral, Antibacterial, and Antifungal Activities and Structure-activity Relationship. Curr. Org. Chem. 2017, 21, 1920-1934. [CrossRef]

7. Iranshahy, M.; Quinn, R.J.; Iranshahi, M. Biologically active isoquinoline alkaloids with drug-like properties from the genus Corydalis. RSC Adv. 2014, 4, 15900-15913. [CrossRef]

8. Maiti, M.; Kumar, G.S. Polymorphic nucleic Acid binding of bioactive isoquinoline alkaloids and their role in cancer. J. Nucleic Acids 2010, 2010, 593408. [CrossRef]

9. Lu, S.M.; Wang, Y.Q.; Han, X.W.; Zhou, Y.G. Asymmetric hydrogenation of quinolines and isoquinolines activated by chloroformates. Angew. Chem. Int. Ed. 2006, 45, 2260-2263. [CrossRef]

10. Scott, J.D.; Williams, R.M. Chemistry and biology of the tetrahydroisoquinoline antitumor antibiotics. Chem. Rev. 2002, 102, 16691730. [CrossRef]

11. Li, B.; Liu, R.X.; Yang, J.; Luo, J.Y.; Yao, L.; Li, M.Q.; Zheng, X.H.; Jiang, R.; Nie, H.F.; Zhang, S.Y. Iridium-Catalyzed Asymmetric Hydrogenation of Sterically Hindered Cyclic Imines for Enantioselective Synthesis of Tetrahydroisoquinolines. Org. Lett. 2021, 23, 140-144. [CrossRef] [PubMed]

12. Li, D.; Chen, X.C.; Gao, W. Asymmetric Synthesis of C-1-Chiral THIQs with Imines in Isoquinoline Rings. Synthesis 2020, 52, 3337-3355. [CrossRef]

13. Noyori, R.; Ohta, M.; Hsiao, Y.; Kitamura, M.; Ohta, T.; Takaya, H. Asymmetric synthesis of isoquinoline alkaloids by homogeneous catalysis. J. Am. Chem. Soc. 1986, 108, 7117-7119. [CrossRef]

14. Pyne, S.G.; Bloem, P.; Chapman, S.L.; Dixon, C.E.; Griffith, R. Chiral sulfur compounds. 9. Stereochemistry of the intermolecular and intramolecular conjugate additions of amines and anions to chiral (E)- and (Z)-vinyl sulfoxides. Total syntheses of (R)-(+)carnegine and (+)- and (-)-sedamine. J. Org. Chem. 1990, 55, 1086-1093. [CrossRef]

15. Mastranzo, V.M.; Yuste, F.; Ortiz, B.; Sanchez-Obregon, R.; Toscano, R.A.; Garcia Ruano, J.L. Asymmetric Synthesis of (S)-(-)Xylopinine. Use of the Sulfinyl Group as an Ipso Director in Aromatic S-E. J. Org. Chem. 2011, 76, 5036-5041. [CrossRef]

16. De, N.; Yoo, E.J. Recent Advances in the Catalytic Cycloaddition of 1,n-Dipoles. ACS Catal. 2018, 8, 48-58. [CrossRef]

17. Bao, G.; Wang, P.; Li, G.; Yu, C.; Li, Y.; Liu, Y.; He, Z.; Zhao, T.; Rao, J.; Xie, J.; et al. 1,3-Dipolar Cycloaddition between Dehydroalanines and $C, N$-Cyclic Azomethine Imines: Application to Late-Stage Peptide Modification. Angew. Chem. Int. Ed. 2021, 60, 5331-5338. [CrossRef]

18. Hua, T.; Yang, Q.; Xiao, W. Recent Developments of Reactions with C,N-Cyclic Azomethine Imines. Chin. J. Org. Chem. 2020, 40, 3559-3595. [CrossRef]

19. Qiu, G.; Kuang, Y.; Wu, J. N-Imide Ylide-Based Reactions: C-H Functionalization, Nucleophilic Addition and Cycloaddition. Adv. Synth. Catal. 2014, 356, 3483-3504. [CrossRef]

20. Yue, G.; Liu, B. Research Progress on $3+n(n \geq 3)$ cycloaddition of 1,3-Diploes. Chin. J. Org. Chem. 2020, 40, 3132-3153. [CrossRef]

21. Hashimoto, T.; Maruoka, K. Recent Advances of Catalytic Asymmetric 1,3-Dipolar Cycloadditions. Chem. Rev. 2015, 115, 5366-5412. [CrossRef] [PubMed]

22. Hashimoto, T.; Maeda, Y.; Omote, M.; Nakatsu, H.; Maruoka, K. Catalytic Enantioselective 1,3-Dipolar Cycloaddition of C,N-Cyclic Azomethine Imines with alpha, beta-Unsaturated Aldehydes. J. Am. Chem. Soc. 2010, 132, 4076-4077. [CrossRef]

23. Hashimoto, T.; Omote, M.; Maruoka, K. Asymmetric Inverse-Electron-Demand 1,3-Dipolar Cycloaddition of C,N-Cyclic Azomethine Imines: An Umpolung Strategy. Angew. Chem. Int. Ed. 2011, 50, 3489-3492. [CrossRef]

24. Li, W.; Wei, J.; Jia, Q.; Du, Z.; Zhang, K.; Wang, J. Asymmetric Synthesis of Tetrahydroquinolines through a $3+2$ Cycloaddition Controlled by Dienamine Catalysis. Chem. Eur. J. 2014, 20, 6592-6596. [CrossRef] [PubMed]

25. Li, W.; Jia, Q.; Du, Z.; Zhang, K.; Wang, J. Amine-Catalyzed Enantioselective 1,3-Dipolar Cycloadditions of Aldehydes to C,N-Cyclic Azomethine Imines. Chem. Eur. J. 2014, 20, 4559-4562. [CrossRef]

26. Chen, L.; Yang, G.M.; Wang, J.; Jia, Q.F.; Wei, J.; Du, Z.Y. An efficient 4+3 cycloaddition reaction of aza-o-quinodimethanes with C,N-cyclic azomethine imines: Stereoselective synthesis of 1,2,4-triazepines. RSC Adv. 2015, 5, 76696-76699. [CrossRef]

27. Zhan, G.; Shi, M.-L.; He, Q.; Du, W.; Chen, Y.-C. 4 + 3 Cycloadditions with Bromo-Substituted Morita-Baylis-Hillman Adducts of Isatins and $N$-(ortho-Chloromethyl)aryl Amides. Org. Lett. 2015, 17, 4750-4753. [CrossRef] [PubMed] 
28. Liu, X.; Wang, Y.; Yang, D.; Zhang, J.; Liu, D.; Su, W. Catalytic Asymmetric Inverse-Electron-Demand 1,3-Dipolar Cycloaddition of $C, N$-Cyclic Azomethine Imines with Azlactones: Access to Chiral Tricyclic Tetrahydroisoquinolines. Angew. Chem. Int. Ed. 2016, 55, 8100-8103. [CrossRef]

29. Liu, X.; Yang, D.; Wang, K.; Zhang, J.; Wang, R. A catalyst-free 1,3-dipolar cycloaddition of C,N-cyclic azomethine imines and 3-nitroindoles: An easy access to five-ring-fused tetrahydroisoquinolines. Green Chem. 2017, 19, 82-87. [CrossRef]

30. Xu, J.; Yuan, S.; Peng, J.; Miao, M.; Chen, Z.; Ren, H. Base-mediated diastereoselective 4+3 annulation of in situ generated ortho-quinone methides with C,N-cyclic azomethine imines. Org. Biomol. Chem. 2017, 15, 7513-7517. [CrossRef] [PubMed]

31. Soeta, T.; Tamura, K.; Ukaji, Y. $5+1$ Cycloaddition of C,N-Cyclic N'-Acyl Azomethine Imines with Isocyanides. Org. Lett. 2012, 14, 1226-1229. [CrossRef] [PubMed]

32. Zhang, L.; Liu, H.; Qiao, G.; Hou, Z.; Liu, Y.; Xiao, Y.; Guo, H. Phosphine-Catalyzed Highly Enantioselective $3+3$ Cycloaddition of Morita-Baylis-Hillman Carbonates with C,N-Cyclic Azomethine Imines. J. Am. Chem. Soc. 2015, 137, 4316-4319. [CrossRef]

33. Wang, K.-K.; Li, Y.-L.; Wang, Z.-Y.; Hu, M.-W.; Qiu, T.-T.; Zhu, B.-K. Cross 1,3-dipolar cycloadditions of C,N-cyclic azomethine imines with an $N$-benzyl azomethine ylide: Facile access to fused tricyclic 1,2,4-hexahydrotriazines. Org. Biomol. Chem. 2019, 17, 244-247. [CrossRef] [PubMed]

34. Cheng, X.; Cao, X.; Xuan, J.; Xiao, W.-J. Silver(I)- and Base-Mediated $3+3$-Cycloaddition of C,N-Cyclic Azomethine Imines with Aza-oxyallyl Cations. Org. Lett. 2018, 20, 52-55. [CrossRef] [PubMed]

35. Cao, W.-B.; Jiang, S.; Li, H.-Y.; Xu, X.-P.; Ji, S.-J. Synthesis of strained 1,2-diazetidines via $3+1$ cycloaddition of C,N-cyclic azomethine imines with isocyanides and synthetic derivation dagger. Org. Chem. Front. 2021. [CrossRef]

36. Zhan, G.; He, Q.; Yuan, X.; Chen, Y.-C. Asymmetric Direct Vinylogous Michael Additions of Allyl Alkyl Ketones to Maleimides through Dienamine Catalysis. Org. Lett. 2014, 16, 6000-6003. [CrossRef]

37. Freedman, T.B.; Cao, X.; Dukor, R.K.; Nafie, L.A. Absolute configuration determination of chiral molecules in the solution state using vibrational circular dichroism. Chirality 2003, 15, 743-758. [CrossRef]

38. Stephens, P.J.; Harada, N. ECD cotton effect approximated by the Gaussian curve and other methods. Chirality 2010, 22, 229-233. [CrossRef] [PubMed]

39. Kong, F.-D.; Ma, Q.-Y.; Huang, S.-Z.; Wang, P.; Wang, J.-F.; Zhou, L.-M.; Yuan, J.-Z.; Dai, H.-F.; Zhao, Y.-X. Chrodrimanins K-N and Related Meroterpenoids from the Fungus Penicillium sp. SCS-KFD09 Isolated from a Marine Worm, Sipunculus nudus. J. Nat. Prod. 2017, 80, 1039-1047. [CrossRef] [PubMed]

40. Bencivenni, G.; Galzerano, P.; Mazzanti, A.; Bartoli, G.; Melchiorre, P. Direct asymmetric vinylogous Michael addition of cyclic enones to nitroalkenes via dienamine catalysis. Proc. Natl. Acad. Sci. USA 2010, 107, 20642-20647. [CrossRef]

41. Ramachary, D.B.; Reddy, Y.V. Dienamine Catalysis: An Emerging Technology in Organic Synthesis. Eur. J. Org. Chem. 2012, 2012, 865-887. [CrossRef]

42. Jurberg, I.D.; Chatterjee, I.; Tannert, R.; Melchiorre, P. When asymmetric aminocatalysis meets the vinylogy principle. Chem. Commun. 2013, 49, 4869-4883. [CrossRef] [PubMed]

43. Na, R.; Jing, C.; Xu, Q.; Jiang, H.; Wu, X.; Shi, J.; Zhong, J.; Wang, M.; Benitez, D.; Tkatchouk, E.; et al. Phosphine-Catalyzed Annulations of Azomethine Imines: Allene-Dependent [3 + 2], [3+3], [4+3], and [3+2+3] Pathways. J. Am. Chem. Soc. 2011, 133, 13337-13348. [CrossRef]

44. Chatzopoulou, E.; Davies, P.W. Highly regioselective synthesis of 2,4,5-(hetero)aryl substituted oxazoles by intermolecular [3 + 2]-cycloaddition of unsymmetrical internal alkynes. Chem. Commun. 2013, 49, 8617-8619. [CrossRef] [PubMed]

45. Zhao, J.; Wu, C.; Li, P.; Ai, W.; Chen, H.; Wang, C.; Larock, R.C.; Shi, F. Synthesis of Pyrido[1,2-b]indazoles via Aryne [3 + 2] Cycloaddition with N-Tosylpyridinium Imides. J. Org. Chem. 2011, 76, 6837-6843. [CrossRef] [PubMed]

46. Zhou, M.-Y.; Kong, S.-S.; Zhang, L.-Q.; Zhao, M.; Duan, J.-A.; Ou-yang, Z.; Wang, M. CuBr2 catalyzed bromination/oxidation of isochromans to benzaldehyde derivatives. Tetrahedron Lett. 2013, 54, 3962-3964. [CrossRef]

47. Wang, K.-K.; Li, Y.-L.; Wang, X.-Y.; Zhu, B.-K. Catalyst-Free Synthesis of 2,3-Benzodiazepines via Tetrahydrodiazirino[3,1a]isoquinoline Reacts with Sulfonyl Chlorides. Chem. Sel. 2019, 4, 3340-3343. [CrossRef]

48. Hickin, J.A.; Ahmed, A.; Fucke, K.; Ashcroft, M.; Jones, K. The synthesis and structure revision of NSC-134754. Chem. Commun. 2014, 50, 1238-1240. [CrossRef]

49. Ortega, H.; Ahmed, S.; Alper, H. Facile Regioselective Synthesis of Pyrazolo[5,1-a]isoquinolines via Ring-Opening Cyclization/Oxidation Reactions of Stable Aroyldiaziridines of 3,4-Tetrahydroisoquinoline with Alkynes. Synthesis 2007, $2007,3683-3691$. [CrossRef]

50. Koptelov, Y.B.; Saik, S.P.; Molchanov, A.P. Stable azomethine imines having a 3,4-dihydroisoquinoline fragment and their cycloaddition to $N$-arylmaleimides. Russ. J. Org. Chem. 2011, 47, 537-546. [CrossRef]

51. Allen, J.M.; Lambert, T.H. Synthesis and characterization of a diaziridinium ion. Conversion of 3,4-dihydroisoquinolines to 4,5-dihydro-3H-benzo[2,3]diazepines via a formal $N$-insertion process. Tetrahedron 2014, 70, 4111-4117. [CrossRef]

52. Nahm, S.; Weinreb, S.M. N-methoxy-n-methylamides as effective acylating agents. Tetrahedron Lett. 1981, 22, 3815-3818. [CrossRef]

53. Larock, R.C.; Lu, Y.-d. Synthesis of allylic ketones via acylation of allylic mercurials. Tetrahedron Lett. 1988, 29, 6761-6764. [CrossRef]

54. Shionhara, T.; Suzuki, K. Facile one-pot procedure for Et3Al-Promoted asymmetric pinacol-type rearrangement. Synthesis 2003, 1, 141-146. [CrossRef] 
55. Lee, A.S.-Y.; Wang, S.-H.; Chang, Y.-T.; Chu, S.-F. Synthesis of $\beta$-Amino and $\beta$-Methoxy Ketones by Lewis Acids Promoted $\beta$-Substitution Reactions of $\beta, \gamma$-Unsaturated Ketones. Synlett 2003, 2003, 2359-2363. [CrossRef]

56. Meninno, S.; Croce, G.; Lattanzi, A. Asymmetric Synthesis of Trisubstituted Tetrahydrothiophenes Bearing a Quaternary Stereocenter via Double Michael Reaction Involving Dynamic Kinetic Resolution. Org. Lett. 2013, 15, 3436-3439. [CrossRef] [PubMed]

57. Zhu, B.; Zhang, W.; Lee, R.; Han, Z.; Yang, W.; Tan, D.; Huang, K.-W.; Jiang, Z. Direct Asymmetric Vinylogous Aldol Reaction of Allyl Ketones with Isatins: Divergent Synthesis of 3-Hydroxy-2-Oxindole Derivatives. Angew. Chem. Int. Ed. 2013, 52, 6666-6670. [CrossRef]

58. Zhuo, L.-G.; Yao, Z.-K.; Yu, Z.-X. Synthesis of Z-Alkenes from Rh(I)-Catalyzed Olefin Isomerization of $\beta, \gamma$-Unsaturated Ketones. Org. Lett. 2013, 15, 4634-4637. [CrossRef] [PubMed]

59. Wang, M.; Lin, L.; Shi, J.; Liu, X.; Kuang, Y.; Feng, X. Asymmetric Crossed-Conjugate Addition of Nitroalkenes to Enones by a Chiral Bifunctional Diamine Organocatalyst. Chem. Eur. J. 2011, 17, 2365-2368. [CrossRef] 